\title{
IMPACT OF POST STENT DEPLOYMENT BALLOON DILATATION DURING PRIMARY PERCUTANEOUS CORONARY INTERVENTION ON LONG-TERM OUTCOMES
}

\author{
Reem Farid, Amr Zaki, Mohammad Sadaka, Sherif Ayad \\ Department of Cardiology, Faculty of Medicine, Alexandria University, Alexandria, Egypt
}

\section{ABSTRACT}

Background:L Post stent balloon dilatation (PSBD) with noncompliant balloon during primary percutaneous coronary intervention (PPCI) is performed in clinical practice in order to optimize stent expansion. However, current knowledge about its use is controversial.

Aim: The aim of this work was to study the impact of post stent balloon dilatation during PPCI on long-term outcomes.

Methods: A total of 307 STEMI patients were recruited in this study. The mean age was $56.80 \pm 11.43$ years, $86 \%$ were males and $14 \%$ were females. Patients had PPCI with drug eluting stents (DES) deployed with or without PSBD according to operator's discretion. Patients were divided in two groups based on PSBD procedure; 212 were subjected to PSBD with non-compliant balloon (group I) and 95 patients without performing PSBD (group II). Coronary angiography of the patients was evaluated before and after stent implantation. The angiographic data, clinical periprocedural, post- procedural and 12 month follow up were compared between the 2 groups.

Results: PSBD performed in 212 patients $(69.1 \%)$. DES were used for all patients. Angiographic parameters for peri-procedural and postprocedural outcomes were compared for the 2 groups. TIMI flow showed statistical significance between the 2 groups $(P=0.007)$. Follow-up during 12 months showed the overall complication rates were lower in PSBD group 20.3 vs 35.8 ( $\mathrm{P}=0.005)$. Stent restenosis (ISR), stent thrombosis and target vessel revascularization (TVR) rates were lower in PSBD; $6.6 \%$ vs $18.9 \%(\mathrm{P}=0.001), 9.0 \%$ vs $20.0 \%(\mathrm{P}=0.007)$ and $4.7 \%$ vs $16.8 \%(\mathrm{P}<0.001)$ respectively.

Conclusion: Adjunctive PSBD with non-compliant balloon has shown to improve post-procedural stent apposition in turn leads to reducing the rate of ISR, stent thrombosis and TVR.

\section{INTRODUCTION}

Ouring ptimization of stent deployment during percutaneous coronary intervention (PCI) is a key element to obtain most favorable immediate and long-term results. ${ }^{(1)}$ Major limitation for the use of stent in the treatment of coronary artery disease is development of stent restenosis and stent thrombosis DES has greatly reduced restenosis rates, and obviated the need for TVR in the majority of patients undergoing PCI, although, TVR still occurs in some of them. ${ }^{2}$
Post-stenting balloon dilation (PSBD) is performed after stent deployment to improve stent expansion. PSBD is associated with improvement of stent deployment and better angiographic results in percutaneous coronary intervention (PCI). However, it had not been evaluated competently in setting of acute coronary syndrome (ACS) undergoing PCI. There are limited data regarding the impact of post-stenting balloon dilatation on long term clinical outcomes in ACS patients. (3) There have been some concerns about the risks of adjunctive balloon post-dilatation, particularly in the setting of acute coronary syndrome (ACS). Therefore, PSBD remains at operators' discretion in clinical practice as well as in large interventional trials. ${ }^{(4)}$

The aim of the present work was to study the impact of post stent deployment balloon dilatation during primary percutaneous coronary intervention on in-hospital and longterm outcomes.

\section{METHODS}

This study was a prospective and retrospective and was conducted on 307 ST elevation myocardial infarction (STEMI) patients collected from Alexandria Main University Hospital and International Cardiac Center (ICC). The study included 264 male patients $(86 \%)$ and 43 female patients (14\%). Their ages ranged from 26-85 years. All patients were evaluated by history taking [especially for dyslipidemia (fasting cholesterol $>200 \mathrm{mg} / \mathrm{dl}$ or on treatment), hypertension (systolic blood pressure $>140 / 90 \mathrm{mmHg}$ or on treatment), Diabetes mellitus and special habits], clinical examination, routine laboratory investigations and 12lead ECG. Coronary angiography including culprit vessel and whether the patient has single or multi vessel disease and PCI data were recorded. Procedural and long term outcome complications were recorded in a retrospective manner from the 1 st of January 2016 till end of May 2017 and in prospective manner from the 1st of June 2017 till end of November 2017. 


\section{STATISTICAL ANALYSIS OF THE DATA}

Data were fed to the computer and analyzed using IBM SPSS software package version 20.0. (Armonk, NY: IBM Corp). Qualitative data were described using number and percent. Quantitative data were described using range (minimum and maximum), mean, standard deviation and median. Significance of the obtained results was judged at the $5 \%$ level. I

The used tests were: 1 - Chi-square test: For categorical variables, to compare between different groups. 2 Fisher's Exact or Monte Carlo correction: Correction for chi-square when more than $20 \%$ of the cells have expected count less than 5. 3 - Mann Whitney test: For abnormally distributed quantitative variables, to compare between two studied groups.

\section{RESULTS}

The study included 307 ST elevation myocardial infarction STEMI patients with a mean age of $56.80 \pm$ 11.43 years, $86 \%$ were males and $14 \%$ were females. Patients were categorized into 2 groups based on PSBD procedure; Group I: 212 patients [179 males (84.4\%) and 33 females (15.6\%)] with STEMI who were subjected to primary PCI with PSBD and Group II: 95 patients [85 males $(89.5 \%)$ and 10 females $(10.5 \%)$ ] with STEMI who were subjected to primary PCI without PSBD. Risk factors for both groups are outlined in table 1, There was no statistical significance between the two studied groups regarding the risk factors. The Coronary angiographic data (Table 2) showed that the patients with single vessel disease were $260(84.7 \%)$; 187 patients out of them $(71.9 \%)$ were from group I, whereas $73(28.1 \%)$ from group II. The patients with multi vessel disease were 47 $(15.3 \%) ; 25(53.2 \%)$ patients from group I, while 22 $(46.8 \%)$ from group II. The culprit vessel was LAD $(55.7 \%)$, RCA $(31.6 \%)$ and $\operatorname{LCX}(12.7 \%)$ respectively. No statistical significance was found between the 2 groups regarding the 3 culprit vessels.
PCI procedural comparative data included: a- Thrombus aspiration catheters: 46 patients $(21.7 \%)$ from group I, and 32 patients $(33.7 \%)$ of group II were managed with thrombus aspiration catheter, This showed statistical significance $(\mathrm{P}=$ 0.026). b- Administration of Glycoprotein IIb/IIIa inhibitors: 42 patients (19.8\%) from group I were given Glycoprotein IIb/IIIa inhibitors, and 20 patients (21.1\%) from group II, there was no statistical significance $(\mathrm{P}=$ 0.802 ). (Table 3 )

Drug eluting stents (DES) were used for all patients. Stent deployment was done with pre-dilatation procedure in $66.9 \%$ of patients and by direct stenting in $33.1 \%$. Stent diameter $\leq 2.75 \mathrm{~mm}$ was used in $14.7 \%$ of patients, while stent diameter $>2.75 \mathrm{~mm}$ was used in $85.3 \%$ of patients. Stent length $\leq 20 \mathrm{~mm}$ was used in $17.5 \%$ of patients, while stent length $>20 \mathrm{~mm}$ was used in $82.5 \%$ of patients. The different types of DES used are illustrated in table 4, there was statistical significance between the 2 studied groups only with SES $(\mathrm{P}=0.023)$.

Post stenting balloon dilatation was performed for 212 of studied patients (group I). The diameter of balloons used was $>2.75 \mathrm{~mm}$ in $82.4 \%$ of patients, while it was $\leq 2.75$ $\mathrm{mm}$ in $17.6 \%$, of them. Balloon length was $<20 \mathrm{~mm}$ in $83.4 \%$ of patients and $\geq 20 \mathrm{~mm}$ in $16.6 \%$ of them.

Procedural outcomes were recorded using TIMI Score (Table 5) which showed statistical significance between the 2 groups with $\mathrm{P}$ value 0.007 . Long term outcome during 12 months follow up are summarized in (Table 6); 230 out of 307 studied patients $(74.9 \%)$ had no complications, the uncomplicated patients among group I were $79.7 \%$ while among group II were $64.2 \%$. Long term complications were collectively estimated in all patients as well as individually for both studied groups. Overall complications were reported in 77 patients (77/307; $25.1 \%) ; 43$ out of them $(43 / 212 ; 20.3 \%)$ were from group I, and 34 patients $(34 / 95 ; 35.8 \%)$ were from group II which showed statistical significance $(P=0.005)$. Stent restenosis (ISR), stent thrombosis and target vessel revascularization (TVR) rates were lower in group I with PSBD; $6.6 \%$ vs $18.9 \% \quad(\mathrm{P}=0.001), 9.0 \%$ vs $20.0 \%$ $(\mathrm{P}=0.007)$ and $4.7 \%$ vs $16.8 \%(\mathrm{P}<0.001)$ respectively.

Table (1): Comparison between the two studied groups according to risk factors

\begin{tabular}{lccccc}
\hline \multicolumn{1}{c}{ Risk factors } & $\begin{array}{c}\text { Total } \\
(\mathbf{n = 3 0 7})\end{array}$ & $\begin{array}{c}\text { Group I } \\
(\mathbf{n = 2 1 2})\end{array}$ & $\begin{array}{c}\text { Group II } \\
(\mathbf{n = 9 5})\end{array}$ & $\chi^{\mathbf{2}}$ & P \\
\hline F.H. for CAD & $75(24.4 \%)$ & $45(21.2 \%)$ & $30(31.6 \%)$ & 3.808 & 0.051 \\
\hline Dyslipidemia & $73(23.8 \%)$ & $52(24.5 \%)$ & $21(22.1 \%)$ & 0.213 & 0.645 \\
\hline HTN & $148(48.2 \%)$ & $105(49.5 \%)$ & $43(45.3 \%)$ & 0.478 & 0.489 \\
\hline DM & $149(48.5 \%)$ & $109(51.4 \%)$ & $40(42.1 \%)$ & 2.276 & 0.131 \\
\hline Smoking & $134(43.6 \%)$ & $85(40.1 \%)$ & $49(51.6 \%)$ & 3.518 & 0.061 \\
\hline
\end{tabular}

$\chi^{2}$ : Chi square test

$\mathrm{p}$ : $\mathrm{p}$ value for comparing between the two studied groups

Table (2): Comparison between the two studied groups according to coronary angiography 


\begin{tabular}{|c|c|c|c|c|c|}
\hline Coronary angiography & $\begin{array}{c}\text { Total } \\
(n=307)\end{array}$ & $\begin{array}{l}\text { Group I } \\
(\mathrm{n}=212)\end{array}$ & $\begin{array}{c}\text { Group II } \\
(\mathbf{n}=95)\end{array}$ & $\chi^{2}$ & $\mathbf{P}$ \\
\hline MVD & $47(15.3 \%)$ & $25(11.8 \%)$ & $22(23.2 \%)$ & $6.536^{*}$ & $0.011^{*}$ \\
\hline SVD & $260(84.7 \%)$ & $187(88.2 \%)$ & $73(76.8 \%)$ & 0.109 & 0.741 \\
\hline \multicolumn{6}{|l|}{ Culprit vessel } \\
\hline LAD & $171(55.7 \%)$ & $126(59.4 \%)$ & $45(47.4 \%)$ & \multirow{3}{*}{5.905} & \multirow{3}{*}{$\begin{array}{l}{ }^{{ }^{M C}} \mathrm{p}= \\
0.089\end{array}$} \\
\hline RCA & $97(31.6 \%)$ & $63(29.7 \%)$ & $34(35.8 \%)$ & & \\
\hline LCX & $39(12.7 \%)$ & $23(10.8 \%)$ & $16(16.9 \%)$ & & \\
\hline
\end{tabular}

Table (3): Comparison between the two studied groups according PCI procedural data

\begin{tabular}{lccccc}
\hline \multicolumn{1}{c}{ PCI procedural data } & $\begin{array}{c}\text { Total } \\
(\mathbf{n = 3 0 7 )}\end{array}$ & $\begin{array}{c}\text { Group I } \\
(\mathbf{n = 2 1 2})\end{array}$ & $\begin{array}{c}\text { Group II } \\
(\mathbf{n = 9 5})\end{array}$ & $\chi^{\mathbf{2}}$ & P \\
\hline Thrombus aspiration & $78(25.4 \%)$ & $46(21.7 \%)$ & $32(33.7 \%)$ & $4.973^{*}$ & $0.026^{*}$ \\
\hline GP IIb/IIIa & $62(20.2 \%)$ & $42(19.8 \%)$ & $20(21.1 \%)$ & 0.063 & 0.802 \\
\hline$\chi^{2}$ Chi $q$ )
\end{tabular}

$\chi^{2}:$ Chi square test

$\mathrm{p}$ : $\mathrm{p}$ value for comparing between the two studied groups

*: Statistically significant at $\mathrm{p} \leq 0.05$

Table (4): Comparison between the two studied groups according to type of stents

\begin{tabular}{lccccc}
\hline \multicolumn{1}{c}{ Type of stent } & $\begin{array}{c}\text { Total } \\
(\mathbf{n = 3 0 7 )}\end{array}$ & $\begin{array}{c}\text { Group I } \\
(\mathbf{n = 2 1 2})\end{array}$ & $\begin{array}{c}\text { Group II } \\
(\mathbf{n = 9 5})\end{array}$ & $\chi^{\mathbf{2}}$ & P \\
\hline Everolimus & $150(48.9 \%)$ & $114(53.8 \%)$ & $36(37.9 \%)$ & 6.62 & 0.101 \\
\hline Sirolimus & $132(43 \%)$ & $82(38.7 \%)$ & $50(52.6 \%)$ & 5.21 & $0.023 *$ \\
\hline Zotralimus & $11(3.6 \%)$ & $9(4.2 \%)$ & $2(2.1 \%)$ & 0.87 & 0.351 \\
\hline Amphilimus & $9(2.9 \%)$ & $4(1.9 \%)$ & $5(5.3 \%)$ & 2.63 & 0.105 \\
\hline Novolimus & $5(1.6 \%)$ & $3(1.4 \%)$ & $2(2.1 \%)$ & 0.2 & 0.659 \\
\hline
\end{tabular}

Table (5): Comparison between the two studied groups according to post procedural outcome according to TIMI score

\begin{tabular}{|c|c|c|c|c|c|}
\hline TIMI score & $\begin{array}{c}\text { Total } \\
(\mathbf{n}=\mathbf{3 0 7})\end{array}$ & $\begin{array}{l}\text { Group I } \\
(n=212)\end{array}$ & $\begin{array}{c}\text { Group II } \\
(n=95)\end{array}$ & $\chi^{2}$ & ${ }^{{ }^{M C}} \mathbf{p}$ \\
\hline 0 & $11(3.6 \%)$ & $9(4.2 \%)$ & $2(2.1 \%)$ & \multirow{4}{*}{$8.882^{*}$} & \multirow{4}{*}{$0.007^{*}$} \\
\hline I & $0(0.0 \%)$ & $0(0.0 \%)$ & $0(0.0 \%)$ & & \\
\hline II & $11(3.6 \%)$ & $3(1.4 \%)$ & $8(8.4 \%)$ & & \\
\hline III & $285(92.8 \%)$ & $200(94.3 \%)$ & $85(89.5 \%)$ & & \\
\hline
\end{tabular}

2: Chi square test MC: Monte Carlo
p: p value for comparing between the two studied groups

$\mathrm{p}: \mathrm{p}$ value for comparing between the
$*$ : Statistically significant at $\mathrm{p} \leq 0.05$

Table (6): Comparison between the two studied groups according to long term follow up complications

\begin{tabular}{lccccc}
\hline $\begin{array}{c}\text { Long term follow up } \\
\text { complications }\end{array}$ & $\begin{array}{c}\text { Total } \\
(\mathbf{n}=\mathbf{3 0 7})\end{array}$ & $\begin{array}{c}\text { Group I } \\
(\mathbf{n = 2 1 2})\end{array}$ & $\begin{array}{c}\text { Group II } \\
(\mathbf{n = 9 5})\end{array}$ & $\chi_{\mathbf{2}}$ & P \\
\hline Restenosis & $32(10.4 \%)$ & $14(6.6 \%)$ & $18(18.9 \%)$ & $10.705^{*}$ & $0.001^{*}$ \\
\hline Stroke & $13(4.2 \%)$ & $9(4.2 \%)$ & $4(4.2 \%)$ & 0.000 & ${ }^{\mathrm{FE}_{\mathrm{p}}=0.999}$ \\
\hline Late thrombosis & $38(12.4 \%)$ & $19(9.0 \%)$ & $19(20.0 \%)$ & $7.369^{*}$ & $0.007^{*}$ \\
\hline TVR & $26(8.5 \%)$ & $10(4.7 \%)$ & $16(16.8 \%)$ & $12.442^{*}$ & $<0.001^{*}$ \\
\hline
\end{tabular}

\footnotetext{
$\chi^{2}$ : Chi square test FE: Fisher Exact

$\mathrm{p}$ : $\mathrm{p}$ value for comparing between the two studied groups

*: Statistically significant at $\mathrm{p} \leq 0.05$
} 


\section{DISCUSSION}

Stent underexpansion is associated with worse outcome following stent implantation. Whether PSBD improves outcome in patients with ACS remains unclear. (5) However, there are no randomized data comparing outcomes following DES deployment with and without postdilatation. ${ }^{(6)}$ In this study, MVD was found in $15.3 \%$ of patients while SVD was found in $84.7 \%$ of them. This was lower than reported in previous studies. ${ }^{(7)}$ It was reported that MVD represents approximately $40-65 \%$ of patients with STEMI referred for PPCI. MVD is associated with high recurrence risk of symptoms and re-admission and higher mortality rates in STEMI patients. ${ }^{(8,9)}$ In the study of Lekston A et al. they reported that in-hospital mortality was $2.9 \%$ vs $9.5 \%(\mathrm{p}<0.0001)$ and the five-year mortality was $11.9 \%$ vs $23.8 \%$ ( $<<0.0001$ ), for SVD vs MVD patients, respectively. The cumulative incidence of MACE during 12-month follow-up was significantly higher in patients with MVD $(32.5 \%$ vs $14.5 \%$, p $<0.0001)^{(7)}$

In the present study, stent deployment was done by predilatation in $66.9 \%$ of patients and by direct stenting in $33.1 \%$ of patients. It was reported that direct stenting has been widely used to improve PCI outcomes in STEMI patients, as it shortens the procedure and saves contrast volume. ${ }^{(10,11)}$ However, apart from procedural aspects, there is no appreciable benefit of direct stenting, as shown by other studies. ${ }^{(12,13)}$

High thrombus burden is still an important predictor of outcome in STEMI patients. In the study of Gao P. et al. 2018, on PSBD in STEMI patients, they found that the usage of thrombus aspiration catheters was more frequent in non- PSBD group than PSBD group $(25.5 \%$ vs. $14.1 \%$, $\mathrm{P}=0.01) .{ }^{(14)}$ These findings are corresponding with the results of current study where only $21.7 \%$ from group I (PSBD) had thrombus aspiration compared with and $33.7 \%$ from group II (non- PSBD). High thrombus burden is still an important predictor of outcome in STEMI patients.

In this study, stent diameter had a significant difference between the two studied groups; patients of group I with PSBD needed a smaller diameter stents than those of group II. Selection of the appropriate stent diameter may be of particular importance during PPCI in cases of AMI.

${ }^{(15)}$ In the present study, stent length $>20 \mathrm{~mm}$ was used in $79.4 \%$ among patients of group I compared with $89.8 \%$ in patients of group II which was statistically significant $(\mathrm{P}=0.004)$. Previous studies showed that long stent length and longer lesion length are predictors of restenosis after DES implantation. In addition, the final optimal stent deployment rate of longer stent deployment lesions was significantly reduced compared to shorter stent deployment lesions after adjuvant PSBD. ${ }^{(16)}$

In the current study, DESs were used for all patients. Everolimus eluting stents EES were the most commonly used for patients of group I (53.8\%). EES appeared to be safe and clinically effective in patients undergoing PCI.
There are now extensive published clinical data supporting the safety and efficacy of EES in comparison with first generation DES. EES have shown less restenosis, stent thrombosis, and periprocedural myocardial infarction. $(17,18)$ On the other hand, Sirolimus eluting stents SES were the most commonly used for group II of studied patients $(52.6 \%)$. It was reported that, the efficacy and safety outcomes after SES implantation remained comparable with those after EES implantation through 3-year followup. However, improvement of clinical outcome after EES implantation compared with SES implantation was suggested by the significantly lower cumulative incidences of TVR. ${ }^{(19,20)}$

In the current study, the rate of no-reflow phenomenon detected after PCI was found to be more among patients of group I with PSBD (4.2\%) than those of group II (2.1\%) without PSBD. This result is consistent with the result reported by Biswas et al. 2012; they clarified the effect of PSBD on immediate TIMI flow which was significantly slower after PSBD. ${ }^{(4)}$ Other studies reported that PSBD during PPCI may increase the risk of suboptimal TIMI flow immediately following post-dilatation, yet PSBD is important to achieve optimal stent expansion and strut apposition for better long term clinical outcomes. ${ }^{(21)}$

It was reported by Gao P. et al. 2018 that PSBD during PPCI procedures causes impairment and slowing of TIMI flow after stent deployment. ${ }^{(14)}$ Their finding is against what was found in the current study, where low reflow TIMI after the PSBD procedure was found to be significantly less in group I (PSBD) compared with group II (no PSBD); $1.4 \%$ vs $8.4 \%$.

In the current work the use of adjunctive PSBD following deployment of DES was done in the great majority of studied patients $(69 \%)$. It was reported that adjunctive PSBD with non-compliant balloons can increase MSA and decrease the frequency of suboptimal stent deployment and potentially reduce the frequency of stent thrombosis and TVR. ${ }^{(3)}$ Many interventionalists have considered that adjunctive PSBD may not be necessary with DES deployment. However, TVR still occurs in 7-9\% of patients following DES implantation, and stent thrombosis remains a major concern. This has stimulated the interest in the role of PSBD following DES implantation to help further improve outcomes. ${ }^{(22)}$ In the study of Karamasis G. et al. 2018, it was also proven that stent optimization by PSBD in STEMI patients undergoing PPCI improved significantly stent expansion and apposition without a significant effect on coronary microcirculation. ${ }^{(23)}$

In the current study, the balloons used for the majority of group I patients subjected to PSBD were $>2.75 \mathrm{~mm}$ in diameter and $<20 \mathrm{~mm}$ in length. It was reported that PSBD using larger balloons at very high pressure could be associated with a very small risk of vessel rupture and a small risk of edge tears. ${ }^{(6)}$

In the present study, the overall complications were found in $20.3 \%$ among patients of group I treated with PSBD compared to $35.8 \%$ among patients of group II with no 
PSBD, which was statistically significant $(\mathrm{P}=0.005)$. Abdelshafi et al, 2018, reported that total MACE after 5 years follow up was $9.8 \%$ among patients had PSBD compared with $12.6 \%$ for those with no PSBD. ${ }^{(180)}$ In another study of Karjalainen PP. et al. 2016, their results had shown that patients who underwent PSBD had less frequent non-fatal MI events at long-term follow-up, compared with those who did not have PSBD $(4.5 \%$ versus $8.5 \%$, respectively, $\mathrm{p}=0.02) .{ }^{(24)}$ On the other hand, the finding of current study was against that reported in the study of Gao P. et al. 2018, who reported $14.4 \%$ MACE among PSBD patients compared by $0.6 \%$ for those without PSBD. ${ }^{(14)}$ Also, Fröbert et al. 2013 found that PSBD was associated with a higher risk of restenosis, contrary to their expectation. ${ }^{(25)}$

In the present study, restenosis was found to be $6.6 \%$ among patients of group I, compared by $18.9 \%$ for patients of group II which was statistically significant $(\mathrm{P}=$ 0.001). This result was similar to that reported in the Turkish study of Yazici HU et al, 2014. They found restenosis risk after PSBD was $3.2 \%$ vs $20.7 \%$ with no PSBD. ${ }^{(26)}$ On the contrary, this finding was against the study of Fröbert et al. 2013, who reported a higher restenosis risk following PSBD. They explained it that PSBD in itself is injurious. Another possible explanation could be that operators tend to use this adjunct in PCIs of lesions confined with a known increased risk of restenosis. ${ }^{(26)}$

In the Turkish study of Tasal A et al. 2013, it was reported that PSBD decrease probability of stent thrombosis and TVR. ${ }^{(27)}$ On the other hand, Gao P. et al. 2018, reported that PSBD is likely to increase the probability of TVR and ISR within one year. ${ }^{(14)}$ In the current study, late thrombosis was found to be $9 \%$ among patients of group I (PSBD), compared by $20 \%$ for patients of group II (no PSBD), this was statistically significant $(\mathrm{P}=0.007)$. In the large Chinese study of Gao $\mathrm{Z}$ et al. 2008, comparing patients who underwent DES implantation with PSBD to those without PSBD, they showed that by angiographic evaluation, in-stent and in-segment restenosis rates at seven-month follow-up was lower in the PSBD group. However, there was no difference in the incidence of TVR or in-stent thrombosis between the two groups. The investigators explained their results that not all angiographic restenosis led to MACE. (28)

In the current study, TVR was found to be $4.7 \%$ among patients of group I, compared to $16.8 \%$ for patients of group II, which was statistically significant $(\mathrm{P}<0.001)$. This result was consistent with the result of Abdeshafi et al. 2018, who reported TVR as 5.4\% among patients with PSBD compared with $7.4 \%$ for those with no PSBD. ${ }^{(3)}$ On the contrary, Gao P. et al. 2018, found that TVR was $5.6 \%$ among PSBD patients compared with $0.8 \%$ in no PSBD patients with STEMI during follow up from 1-12 months. ${ }^{(14)}$

Abdelshafi et al, 2018, during their follow up study reported the incidence of stroke among patients underwent PSBD as $14 \%$ while it was $17.6 \%$ among nonPSBD patients, which was statistically significant. ${ }^{(3)}$ In the current study, stroke incidence did not show any statistical significant difference between both studied groups.

In conclusion, the effect of PSBD in AMI remains to be clarified as it was more associated with no-reflow phenomenon during PPCI. However, it demonstrated favorable clinical outcomes at long term follow-up.

\section{EFERENCES}

1. Brodie BR, Cooper C, Jones M, Fitzgerald P, Cummins F. Is adjunctive balloon postdilatation necessary after coronary stent deployment? Final results from the POSTIT trial. Catheter Cardiovasc Interv 2003;59: 184-92.

2. Fujii K, Carlier SG, Mintz GS, Yang YM, Moussa I, Weisz G, et al. Stent underexpansion and residual reference segment stenosis are related to stent thrombosis after sirolimuseluting stent implantation: an intravascular ultrasound study. J Am Coll Cardiol 2005; 45: 995-8.

3. Abdelshafi K, Rha SW, Park JY, Choi BG, Choi SY. Impact of Post-stenting Balloon Dilatation on 5-year Clinical Outcomes in Patients with Acute Coronary Syndrome underwent Percutaneous Coronary Intervention. J Am Coll Cardiol 2018; 72(13) Suppl B: 99.

4. Biswas S, Soon K, Lim Y. Adjunctive balloon dilatation after stent deployment: Beneficial or deleterious? Int $\mathbf{J}$ of Cardiol 2012; 157:3-7.

5. Karjalainen PP, Niemelä M, Laine M, Airaksinen JK, Ylitalo A, Nammas W. Usefulness of Post-Coronary Dilatation to Prevent Recurrent Myocardial Infarction in Patients Treated with Percutaneous Coronary Intervention for Acute Coronary Syndrome (From the BASE ACS Trial), The American Journal of Cardiology (2016), doi: 10.1016/j.amjcard.2016.09.057.

6. Iakovou I, Mintz GS, Dangas G, Abizaid A, Mehran R, Kobayashi Y, et al. Increased CK-MB release is a "tradeoff" for optimal stent implantation: An intravascular ultrasound study. J Am Coll Cardiol 2003; 42:1900-5.

7. Lekston A, Tajstra M, Gąsior M, Gierlotka M, Pres D, Hudzik B, et al. Impact of multivessel coronary disease on one-year mortality in patients with ST elevation myocardial infarction undergoing percutaneous coronary intervention. Kardiol Pol 2011; 69:336-43.

8. de Waha S, Eitel I, Desch S, Fuernau G, Pöss J, Schuler G, Thiele H. Impact of multivessel coronary artery disease on reperfusion success in patients with ST elevation myocardial infarction: A substudy of the AIDA STEMI trial. Eur Heart J Acute Cardiovascular Care 2018; 7:28-37.

9. Batra MK, Rasool SI, Solangi BA, Khan N, KarimM, Hassan Rizvi SN. Multivessel Disease as A Prognostic Marker In Patients Presenting For Primary Percutaneous Coronary Intervention. J Ayub Med Coll Abbottabad 2018; 30(4): 534-8.

10. Barbato E, Marco J, Wijns W. Direct stenting. Euro Heart J 2003; 24:394-403.

11. Azzalini L, Millán X, Ly HQ, L'Allier PL, Jolicoeur EM. Direct stenting versus pre-dilation in ST-elevation myocardial infarction: a systematic review and metaanalysis. J Interv Cardiol 2015; 28(2):119-31.

12. Mahmoud KD, Jolly SS, James S, Dzavik V, Cairns JA, et al. Clinical impact of direct stenting and interaction with thrombus aspiration in patients with ST-segment elevation myocardial infarction undergoing percutaneous coronary intervention: Thrombectomy Trialists Collaboration. Eur Heart J 2018; 39:2472- 9. 
13. Neumann F, Gick M. Direct stenting in ST-elevation myocardials infarction: convenient, but not improving outcomes. Eur Heart J 2018; 39(26):2480-3.

14. Gao P, Lin W, Wang H, Du F. Application of postdilation in ST-segment elevation myocardial infract patients undergoing primary percutaneous coronary intervention. Int J Clin Exp Med 2018; 11(11):12657-63.

15. Kuntz RE, Safian RD, Carrozza JP, Fishma RF, Mansour M, Baim DS. The importance of acute luminal diameter in determining restenosis after coronary atherectomy or stenting. Circulation 1992; 86:1827-35.

16. Kim BG, Cho SW, Kim DH, Kim JH, Byun YS, Goh $\mathrm{CW}$, et al. Stent length is a contributing factor of suboptimal stent expansion in drug-eluting stents. Kardiol Pol 2015; 73(8):598-605.

17. Yano $H$, Horinaka $S$, Ishimitsu T. Impact of everolimuseluting stent length on long-term clinical outcomes of percutaneous coronary intervention. $\mathbf{J}$ of Cardiol 2018; 71(5):444-51.

18. Townsend JC, Rideout P, Steinberg DH. Everolimuseluting stents in interventional cardiology. Vasc Health Risk Manag 2012; 8:393-405.

19. Tahara S, Bezerra HG, Kyono H, Carrigan T, Mehanna $\mathrm{E}$, Wang $\mathrm{W}$, et al. Impact of acute gain on clinical outcomes of patients treated with sirolimus-eluting stent A sub-analysis study from the STLLR trial. Circ J 2011; 75:2113-19.

20. Costa MA, Angiolillo DJ, Tannenbaum M, Driesman M, Chu A, Patterson J, et al. STLLR Investigators. Impact of stent deployment procedural factors on long-term effectiveness and safety of sirolimus-eluting stents (final results of the multicenter prospective STLLR trial). Am J Cardiol 2008; 101:1704-11.

21. Mahmoud I, Hosny M, Fawzy M, Ragab D, El-Atroush H. TIMI Risk Score as a Predictor for No-Reflow Phenomenon in Patients Undergoing Primary Angioplasty for Acute STEMI. Med J Cairo Univ 2017; 85(3):973-6.
22. van der Hoeven BL, Liem SS, Dijkstra J, Bergheanu SC, Putter $\mathrm{H}$, Antoni ML, et al. Stent malapposition after sirolimus eluting and bare-metal stent implantation in patients with ST-segment elevation myocardial infarction: acute and 9-month intravascular ultrasound results of the MISSION! Intervention study. JACC Cardiovasc Interv 2008; 1:192-201.

23. Karamasis G, Kalogeropoulos A, Marco V, Al-Janabi F, Toor I, Cook C, et al. The effects of stent post-dilatation during primary percutaneous coronary intervention (PPCI) for ST-elevation myocardial infarction (STEMI): Insights from optical coherence tomography (OCT) and coronary physiology. J Am College of Cardiol 2018; 72(13) Suppl:1156.

24. Karjalainen P, Niemelä M, Laine M, Airaksinen JK, Ylitalo A, Nammas W. Usefulness of Post-Coronary Dilatation to Prevent Recurrent Myocardial Infarction in Patients Treated with Percutaneous Coronary Intervention for Acute Coronary Syndrome. Am J Cardiol 2017; 119(3):345-50.

25. Fröbert O, Lagerqvist B, Olivecrona GK, Omerovic E, Gudnason T, Maeng M, et al. TASTE Trial. Thrombus aspiration during ST-segment elevation myocardial infarction. N Engl J Med 2013; 369(17):1587-97.

26. Yazıcı HU, Ovalı C, Gamalıyev MA, Aydar Y, Morrad $\mathrm{B}$, Şenol U, et al. The Impact of Post Dilatation on Angiographic Outcomes after Drug Eluting Stent Implantation. The Am J Cardiol 2014; 113(7),Suppl:S2.

27. Tasal A, Bacaksiz A, Vatankulu MA, Turfan MT, Erdogan E, Sonmez O, et al. Is postdilatation with a noncompliant balloon necessary after coronary stent deployment during primary angioplasty? J Interven Cardiol 2013; 26:325-31.

28. Gao Z, Yang YJ, Xu B, Chen JL, Qiao SB, Yao M, et al. Is adjunctive balloon postdilatation necessary with drugeluting stents? One center experience in Chinese patients. Chin Med J 2008; 121:513-7. 